\title{
Silicon Sacrificial Layer Technology for the Production of 3D MEMS (EPyC Process) ${ }^{\dagger}$
}

\author{
Latifa Louriki 1,*, Peter Staffeld ${ }^{1}$, Arnd Kaelberer ${ }^{1}$ and Thomas Otto ${ }^{2}$ \\ 1 Robert Bosch GmbH, Reutlingen D-72762, Germany; Peter.Staffeld@de.bosch.com (P.S.); \\ Arnd.Kaelberer@de.bosch.com (A.K.) \\ 2 Department of Electrical Engineering and Information Technology and Fraunhofer Institute for Electronic \\ Nano Systems ENAS Chemnitz, Technical University Chemnitz-Zwickau, Chemnitz D-09107, Germany; \\ thomas.otto@enas.fraunhofer.de \\ * Correspondence: Latifa.louriki@de.bosch.com \\ + Presented at the Eurosensors 2017 Conference, Paris, France, 3-6 September 2017.
}

Published: 11 August 2017

\begin{abstract}
The EPyC process uses silicon sacrificial layer technology, which makes it possible to generate high volume sacrificial structures of up to 100 microns thickness. The biggest challenge is the rapid and complete removal of the 3D sacrificial structure at the end of the process. This paper examines and compares in detail two silicon dry etching methods to optimize a new silicon etching process for successful EPyC manufacturing.
\end{abstract}

Keywords: 3D MEMS; EPyC process; silicon sacrificial layer technology

\section{Introduction}

The EPyC process is based on cyclic deposition of epitaxial polysilicon and oxide. The silicon is structured by DRIE process to separate sacrificial from functional silicon. The narrow trench gaps are refilled with oxide to protect the functional parts towards the etch gases. The sacrificial structure is finally released by a suitable silicon dry etching process. The remaining oxide passivation is cleaned off the surfaces with HF vapor phase etching. An optimized dry etching process is crucial for the EPyC process [1]. The challenge is to completely remove three dimensional high volume polysilicon sacrificial structures with a high etching rate even in nested areas which are difficult to access. In this paper, two dry etching processes are examined in detail and compared with each other with regard to the requirements of the $\mathrm{EPyC}$ process: the plasma process with sulfur hexafluoride $\left(\mathrm{SF}_{6}\right)$ and the chemical etching process with xenon difluoride $\left(\mathrm{XeF}_{2}\right)$. Both etching methods etch silicon spontaneously and isotropically.

\section{Silicon Dry Etching}

\subsection{Chemical Etching Process with $\mathrm{XeF}_{2}$}

At room temperature the solid $\mathrm{XeF}_{2}$ has a vapor pressure of about 4 Torr. The gaseous $\mathrm{XeF}_{2}$ spontaneously etches silicon. The chemical reaction is shown in Equation (1).

$$
2 \mathrm{XeF}_{2}+\mathrm{Si} \rightarrow 2 \mathrm{Xe}+\mathrm{SiF}_{4}
$$

with this etching process, it is possible to create long undercuts even within extremely narrow structures $(<1 \mu \mathrm{m})$. However, the etch rate is limited by the vapor pressure of the solid $\mathrm{XeF}_{2}$. The etching mechanism has already been described in detail in various papers [2-4]. 


\subsection{The Plasma Process with $S F_{6}$}

In the plasma high-energy electrons collide with $S F_{x}$-molecules and decompose into $S F^{+}{ }_{x-1}$-ions and F-radicals (Equation (2)). The F-radicals react spontaneously with silicon and form the volatile product silicon tetrafluoride $\mathrm{SiF}_{4}$ (Equation (3)).

$$
\begin{gathered}
S F_{x}+e^{-} \rightarrow S F^{+}{ }_{x-1}+F^{*}+2 e^{-} \\
S i+4 F^{*} \rightarrow S i F_{4}
\end{gathered}
$$

The F-radicals also etch silicon isotropically. The limitation of this process is the recombination of the F-radicals [5].

In Figure 1 the etch mechanisms of $\mathrm{SF}_{6}$ and $\mathrm{XeF}_{2}$ is shown.

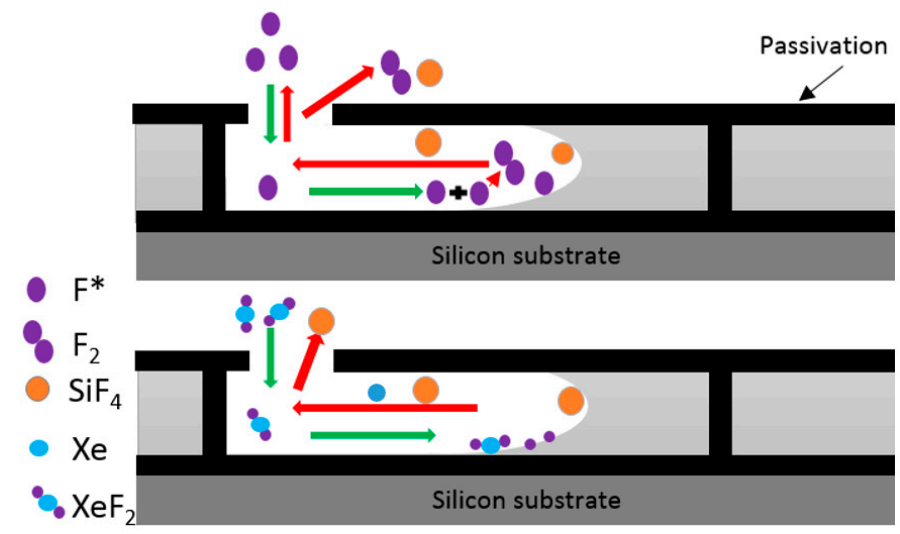

Figure 1. Schematic view of silicon etch process. At the beginning silicon is etched isotropic (all direction). As soon as the sacrificial silicon is cleared to the bottom oxide there is only lateral undercut restricted by the oxide filled trench gaps.

\section{Sample Preparation}

To elucidate the differences between two etching methods, a new set of masks was developed to build up a single EPyC sample for the baseline experiments. For the experiments one-sided polished 8-inch silicon substrate was used. First a $2.5 \mu \mathrm{m}$ thermal oxide is deposited on the substrate (isolation layer). On a thin LPCVD polysilicon seed layer a $20 \mu \mathrm{m}$ epitaxial silicon layer is grown and planarised by CMP (chemical mechanical polishing). The first mask is used to pattern the $20 \mu \mathrm{m}$ silicon layer by DRIE process. A selection of different shapes for the sacrificial silicon is defined by the $1.4 \mu \mathrm{m}$ single gap size mask (black line in Figure 1). The narrow trench gaps are then refilled with $2.2 \mu \mathrm{m}$ LPCVD oxide. The second mask is used to pattern the oxide layer to create a variety of differently shaped etch accesses for $\mathrm{SF}_{6}$ and $\mathrm{XeF}_{2}$ (red areas in Figure 2). The oxide is structured by a $\mathrm{CF}_{4}$ plasma process. The final open area (etch access) with respect to the wafer surface is $0.37 \%$. In our experiments the single EPyC samples are etched stepwise (time intervals) either with $\mathrm{XeF}_{2}$ or $\mathrm{SF}_{6}$-plasma. Both etching processes with $\mathrm{XeF}_{2}$ and $\mathrm{SF}_{6}$ were tuned to get the maximum etch rate. The low open area of $0.37 \%$ allows high etch rates even for the vapor pressure limited $\mathrm{XeF}_{2}$. To determine the lateral etch rate the undercut is measured through the oxide mask by optical microscope. 


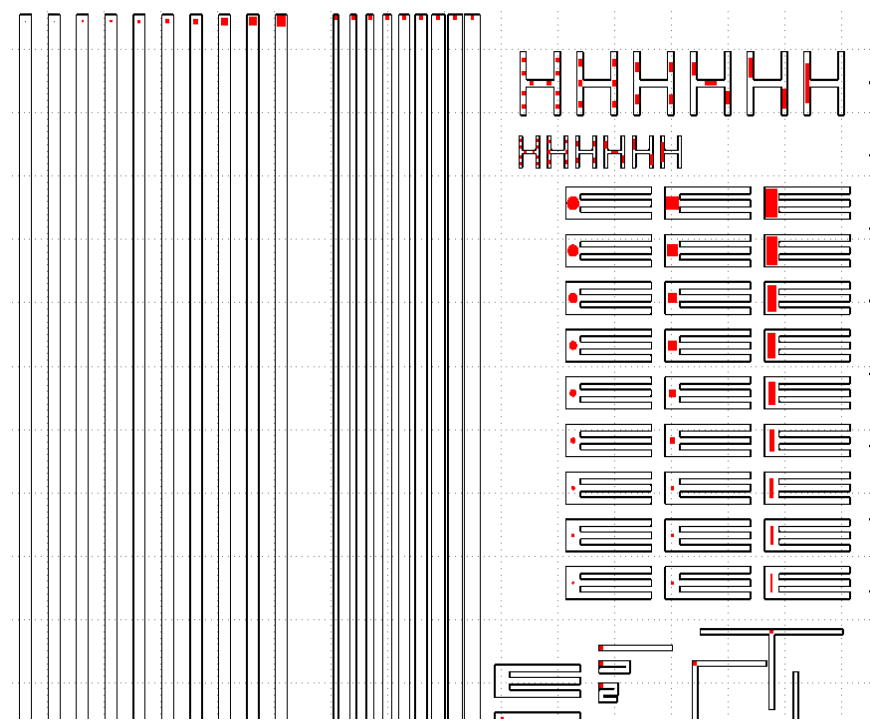

Figure 2. Mask-layers (black line: trench mask, red area: etch-access) for etch experiments. Some examples narrow/wide lines, dense/isolated.

\section{Results}

\subsection{Aperture Size Effect}

To determine the lateral undercut as a function of the size of the aperture $5000 \mu \mathrm{m}$ long and $40 \mu \mathrm{m}$ wide channels with a square shaped etch access on one end were used. The aperture varies from $2 \times 2$ to $30 \times 30 \mu \mathrm{m}^{2}$ in. Figure 3 show the lateral undercut as a function of the aperture size for $\mathrm{SF}_{6}$ and $\mathrm{XeF}_{2}$ after 8 min etch time respectively. For $\mathrm{SF}_{6}$ silicon is hardly etched with small aperture sizes. Between $7 \times 7 \mu \mathrm{m}^{2}$ and $15 \times 15 \mu \mathrm{m}^{2}$ the lateral undercut strongly increases. At $15 \times 15 \mu \mathrm{m}^{2}$ the lateral undercut starts to saturate and remains nearly constant with a maximum etch rate of $\sim 30 \mu \mathrm{m} / \mathrm{min}$. The smaller the access the less fluorine radicals can pass the bottle neck per time unit. In addition the collision probability increases with decreasing access size leading to a strong loss of reactive fluorine radicals due to recombination. Therefore the etch slows down dramatically. With $\mathrm{XeF}_{2}$ etches silicon already with an aperture size of $2 \times 2 \mu \mathrm{m}^{2}$ with $3 \mu \mathrm{m} / \mathrm{min}$. The etch rate strongly increases between $2 \times 2 \mu \mathrm{m}^{2}$ and $15 \times 15 \mu \mathrm{m}^{2}$ where saturation sets in with a maximum etch rate of $\sim 37 \mu \mathrm{m} / \mathrm{min}$. $\mathrm{XeF}_{2}$ shows the same limitation due to diffusion through small cross section access holes but there is no further loss of active species due to chemical reactions.
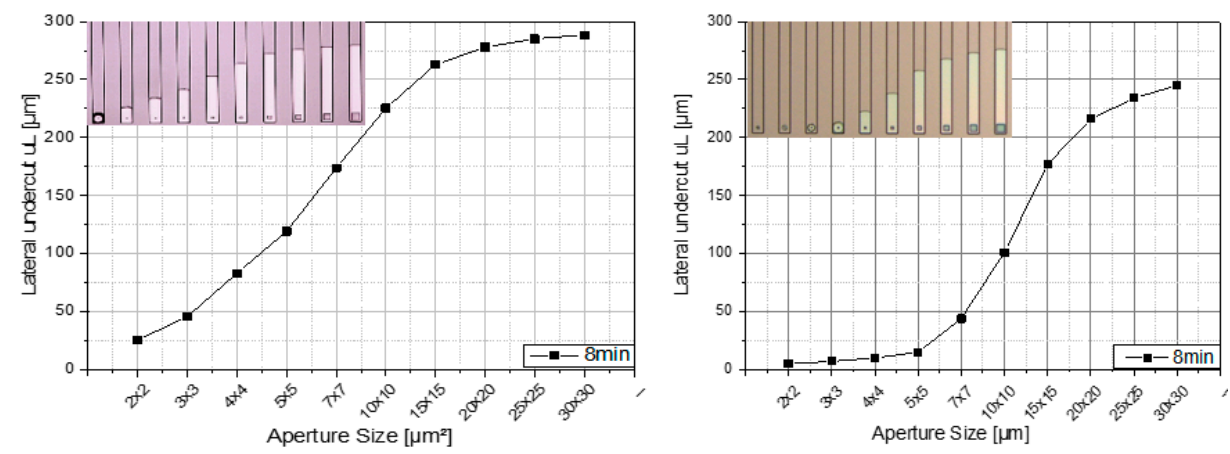

Figure 3. The etch results after 8 min for $\mathrm{XeF}_{2}$ (left) and $\mathrm{SF}_{6}$ (right).

\subsection{Channel Size Effect}

The influence of the channel width on the lateral undercut was investigated by using $5000 \mu \mathrm{m}$ long channels with a fixed square shaped access of $10 \times 10 \mu \mathrm{m}^{2}$ (fixed etch gases quantity) on one end. The channel width was varied between 15.6 and $55.6 \mu \mathrm{m}$ in $5 \mu \mathrm{m}$ steps. By varying the width of the channels the volume of sacrificial silicon to be removed changes. The Figure 4 shows the etch results 
after 2 min and 46 min for $\mathrm{SF}_{6}$ and $\mathrm{XeF}_{2}$. At the beginning etching in all channels is isotropic. After 2 min of etching with $\mathrm{XeF}_{2}$ the narrow channel $(15.6 \mu \mathrm{m})$ shows the longest undercut as expected. As the etch is continued the same etch rate is observed in all different channels. The reaction speed by $\mathrm{XeF}_{2}$ is limited by diffusion only. $\mathrm{SF}_{6}$ shows a larger difference between the channels after 2 min of etching. Therefore there might be no excess of F-radicals during the isotropic part of the etch leading to an additional advantage for the narrow channel. Continuing the etch all channels show very similar etch rates. After $46 \mathrm{~min} \mathrm{SF}_{6}$ shows significantly shorter undercut $(450 \mu \mathrm{m})$ then $\mathrm{XeF}_{2}$ $(1134 \mu \mathrm{m}) . \mathrm{SF}_{6}$ is limited by recombination in a small accesses and diffusion.
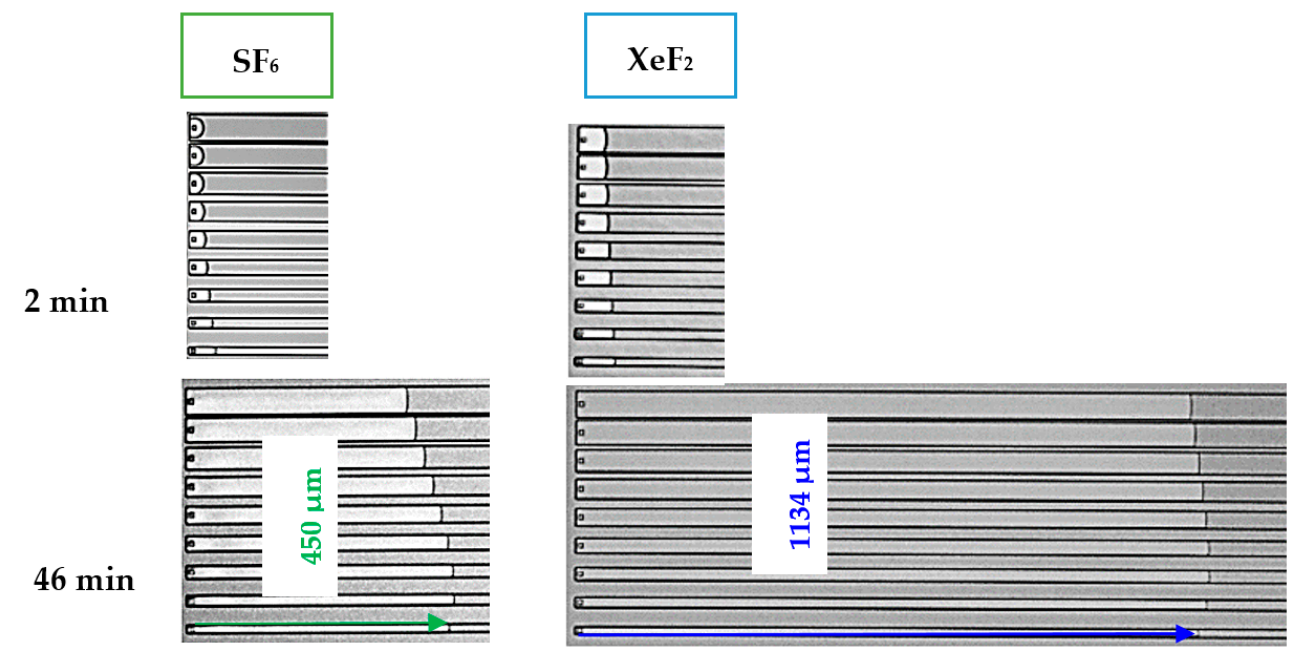

Figure 4. The etch results after $2 \mathrm{~min}$ and $46 \mathrm{~min}$ for $\mathrm{XeF}_{2}$ and $\mathrm{SF}_{6}$.

\subsection{Optimization of the Etching Process by Combining SF6 and XeF2}

To demonstrate the advantage of a process combining $\mathrm{SF}_{6}$ and $\mathrm{XeF}_{2}$ we used a sample with larger open area of $\sim 1 \%$. $\mathrm{XeF}_{2}$ has a clear disadvantage etching high volumes with large open area (vapor pressure). A structure was examined with a larger rectangular access of $45 \mu \mathrm{m}$ width and $95 \mu \mathrm{m}$ length. The channel to be etched is $950 \mu \mathrm{m}$ long and $44 \mu \mathrm{m}$ wide. In Figure 5 it is shown that the etch rate of $\mathrm{SF}_{6}$ at the beginning etching is by a factor 3 higher than the etch rate of $\mathrm{XeF}_{2}$. Then decreases the etch rate of $\mathrm{SF}_{6}$ with the undercut contrary to $\mathrm{XeF}_{2}$ where the etch rate increases with the undercut since the open area of silicon decreases during the etch process. There is a certain undercut length of $\sim 200 \mu \mathrm{m}$ where $\mathrm{XeF}_{2}$ begins to etch faster than $\mathrm{SF}_{6}$. The etch time can be reduced by a factor of 2 to $28 \mathrm{~min}$ by combining both etch methods. The optimum undercut to switch etch gases strongly depends on the layout (open area, aperture size, layer thickness).
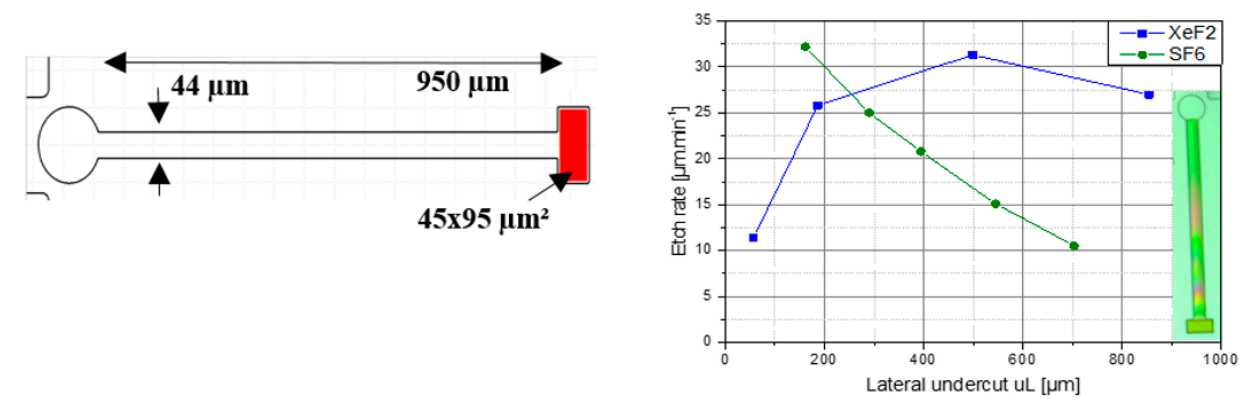

Figure 5. Etching results for same structure of the both etching gases $\mathrm{SF}_{6}$ and $\mathrm{XeF}_{2}$ in different etching time.

\section{Conclusions}

In this paper two dry etching processes were investigated in detail with regard to the requirements of the EPyC process. The plasma-process with sulfur hexafluoride $\left(\mathrm{SF}_{6}\right)$ shows its 
strength in etching high volumes. Vertical etching in the depth and lateral undercut of readily accessible sacrificial silicon of up to $300 \mu \mathrm{m}$ is possible with very high etch rate of $30-40 \mu \mathrm{m} / \mathrm{min}$. The etching rate decreases with increasing undercut. Furthermore, the etch-rate almost comes to a standstill with small etching accesses $\mathrm{d}<6 \mu \mathrm{m}$. The chemical etching process with xenon difluoride $\left(\mathrm{XeF}_{2}\right)$ gas behaves completely different. The strength is in the etching of small volumes in nested sacrificial structures with extreme undercut of $>300 \mu \mathrm{m}$. In this case, etching rates of $30-40 \mu \mathrm{m} / \mathrm{min}$ can also be observed in areas which are difficult to access. The etch rate drops dramatically when $\mathrm{XeF}_{2}$ faces a high open area of silicon. A big advantage was observed in combining both etching methods leading to a much shorter etching time. A rapid and complete removal of 3D sacrificial silicon structures at the end of the multi-layer EPyC process is now possible. Since the process can be adapted towards the individual requirements (high volume or tiny nested structures), the process is ready to face needs of any complexity.

Author Contributions: L.L. and P.S. conceived and designed the experiments; L.L. performed the experiments, analyzed the data, contributed reagents/materials/analysis tools; A.K. contributed in scientific discussions and interpretation of the results; L.L. and P.S wrote the paper with input from all authors. Both P.S and T.O. provided critical feedback. T.O. supervised the project

Conflicts of Interest: The authors declare no conflict of interest.

\section{References}

1. Breitschaedel, O.; Kaelberer, A.; Zielke, C.; Staffeld, P.B.; Artmann, H. Method for Manufacturing Microelectromechanical Structures in A Layer Sequence and a Corresponding Electronic Component Having a Microelectromechanical Structure. US Patent Application 15/097,331, 20 October 2016.

2. Metzger, L.; Fischer, F.; Mokwa, W. Polysilicon Sacrificial Layer Etching Using XeF2 for Silicon Acceleration Sensors with High Aspect Ratio. In Proceedings of the European Conference on Solid-State Transducers, Eurosensors XVI, Prague, Czech Republic, 15-18 September 2002.

3. Chang, F.I.; Yeh, R.; Lin, G.; Chu, P.B.; Hoffman, E.; Kruglick, E.J.J; Pister, K.S.J. Gas-phase silicon micromachining with xenon difluoride. SPIE 1995, 2641, 117-128.

4. Dagata, J.A.; Squire, D.W.; Dulcey, C.S.; Hsu, D.S.Y.; Lin, M.C. Chemical processes involved in the etching of silicon by xenon difluoride. J. Vac. Sci. Technol. B 1987, 5, 1495-1500.

5. Anderson, H.M.; Merson, J.A.; Light, R.W. A kinetic model for plasma etching silicon in a SF6/02 RF discharge. IEEE Trans. Plasma Sci. 1986, 14, 156-164.

(c) 2017 by the authors. Licensee MDPI, Basel, Switzerland. This article is an open access article distributed under the terms and conditions of the Creative Commons Attribution (CC BY) license (http://creativecommons.org/licenses/by/4.0/). 